\title{
Start Relative To Reference Code
}

National Cancer Institute

\section{Source}

National Cancer Institute. Start Relative To Reference Code. NCI Thesaurus. Code C93673.

A coded value specifying when this event started with respect to the sponsor-defined reference period. 